\title{
A Review of Fire Interactions and Mass Fires
}

\author{
Mark A. Finney and Sara S. McAllister \\ USDA Forest Service, Missoula Fire Sciences Laboratory, 5775 Highway 10 West, Missoula, Montana, MT 59808, USA \\ Correspondence should be addressed to Mark A. Finney, mfinney@fs.fed.us
}

Received 27 October 2010; Accepted 22 January 2011

Academic Editor: Paul-Antoine Santoni

Copyright ( 2011 M. A. Finney and S. S. McAllister. This is an open access article distributed under the Creative Commons Attribution License, which permits unrestricted use, distribution, and reproduction in any medium, provided the original work is properly cited.

\begin{abstract}
The character of a wildland fire can change dramatically in the presence of another nearby fire. Understanding and predicting the changes in behavior due to fire-fire interactions cannot only be life-saving to those on the ground, but also be used to better control a prescribed fire to meet objectives. In discontinuous fuel types, such interactions may elicit fire spread where none otherwise existed. Fire-fire interactions occur naturally when spot fires start ahead of the main fire and when separate fire events converge in one location. Interactions can be created intentionally during prescribed fires by using spatial ignition patterns. Mass fires are among the most extreme examples of interactive behavior. This paper presents a review of the detailed effects of fire-fire interaction in terms of merging or coalescence criteria, burning rates, flame dimensions, flame temperature, indraft velocity, pulsation, and convection column dynamics. Though relevant in many situations, these changes in fire behavior have yet to be included in any operational-fire models or decision support systems.
\end{abstract}

\section{Introduction}

Some interactions of wildland fires are experienced routinely under field conditions. Firefighters and prescribed fire personnel see flames tilting towards adjacent ignition points or fire edges, particularly as the sources advance closer together $[1,2]$. In the extreme case, interactions occurring when large areas are ignited and burning simultaneously are described as mass fires, area fires, or "fire storms" [3]. Hundreds or thousands of individual fires may interact over an area and exhibit some "unified" behavior. Such fires are generally described as having such strong indrafts that outward propagation is minimal, extremely tall convection columns or smoke plumes, and burn for long durations until all the fuel within its perimeter is consumed. Good reviews of mass or large area fires can be found in [4-6]. Mass fires were responsible for tremendous burning rates and tornado-strength winds [7] witnessed after the fire bombings of cities in Germany and Japan during World War II $[8,9]$ and have been studied mainly in relation to consequences of nuclear attacks [3, 10-34]. Many of these studies were through "Project Flambeau," a joint effort between the U.S. Office of Civil Defense-Defense Atomic Support Agency and the U.S. Department of Agriculture-Forest Service in the mid-1960s. These fires were designed to mimic a suburb fire. Each square fuel bed was constructed with a mixture of pinyon pine and juniper and was approximately the same size and fuel load as a typical suburban house $\left(185.8 \mathrm{~m}^{2}\right.$ and about $18,000 \mathrm{~kg}$ of fuel). The spacing between fuel beds was either $7.6 \mathrm{~m}$ or $35.1 \mathrm{~m}$ and fire sizes were $2,6,12$, and 20 hectares. Airflow velocities and temperatures were measured inside and just outside the fire area along with thermal radiation just outside the fire area, oxygen and carbon dioxide concentrations inside the fire area, and the mass loss rate of the fuel beds $[3,12,13]$.

Wildland fire interactions are intentionally manipulated for ignition or firing operations (see Figures 1 and 2) to orient spread directions [35], use indrafts for backfire operations [36], increase the development of convection columns on prescribed fires through center-firing techniques [1], and limit spread and intensity with spot fire ignitions [37-39]. Rapid increases in fire growth and energy release-termed "blowup"-are sometimes associated with fire interactions [40]. Yet, despite the common usage and practical familiarity with interactions that fire personnel often acquire, there is very little quantitative physical understanding of these 


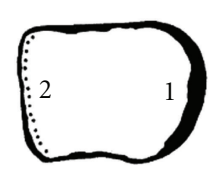

Head fire

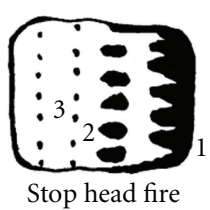

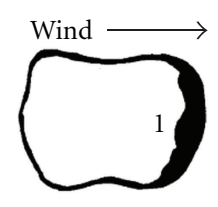

Back fire

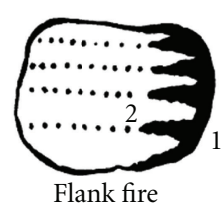

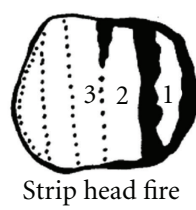

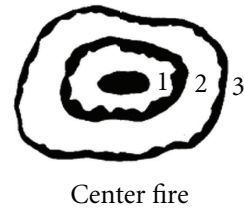

Figure 1: Prescribed fire ignition patterns designed to restrict or enhance fire front interactions [1].

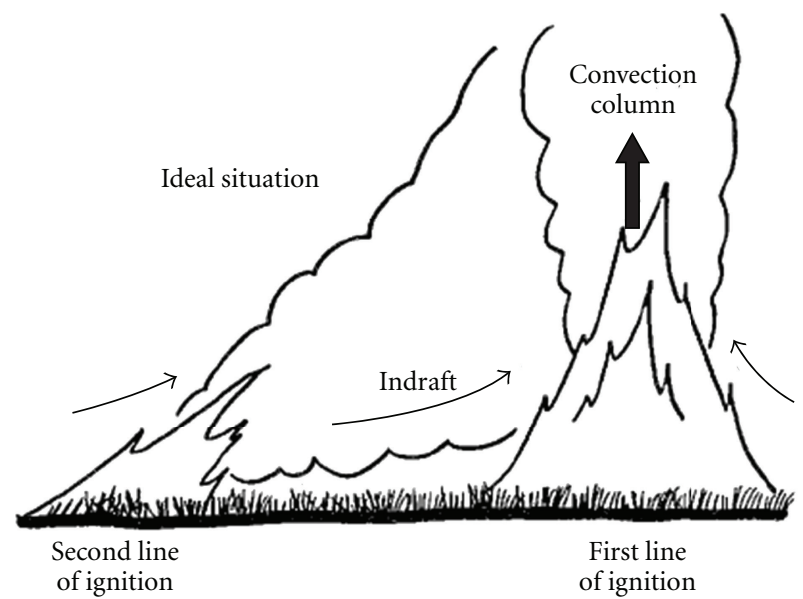

FIGURE 2: Indrafting and flame response of sequential line fires in prescribed burning [2].

behaviors and no operational models that can predict them. By comparison to other fire behavior characteristics, such as fire spread rates, fire interactions at any scale have been subject to limited study.

In this paper, we endeavored to obtain literature from many sources, including wildland fire, structural fire, as well as combustion engineering and fluid dynamics, in order to cover the range of research on fire-fire interactions and the state of knowledge. Our search revealed that the topic of fire interactions overlaps considerably with other fire behaviors that are distinguished individually, such as vortices and terrain effects. These behaviors will be mentioned when appropriate, but their full discussion is beyond the scope of this paper.

\section{Background: Time-Dependent Fire Behaviors}

For a constant set of environmental conditions, fire behavior is known to change with time. These changes are not expressly considered interactions, but spread and intensity changes within individual fires are also affected during interaction among fires, and may contribute to later development of interactions. Thus, such behaviors provide useful background material for discussion of fire-fire interactions, although studies of fire acceleration have not directly addressed interactions of multiple fires. Many of the timedependent changes in fire behavior are associated with fire growth or expansion in two dimensions. Changes are observed in spread rates (acceleration), frontal geometry (width, curvature), and heat transfer indicated by the orientation and size of flames. These fire characteristics are interrelated with spread processes, and the literature does not discern the causes of observable features from their probable effects.

2.1. Fire Acceleration. Fire acceleration is defined as the time-dependent changes in spread and intensity occurring under constant weather and uniform fuel conditions. The notion of acceleration is implicitly applied to fires that are already capable of spreading as compared to combinations of threshold conditions where spread only occurs above some limit. Various mathematical representations of acceleration (Figure 3) have been proposed from a theoretical standpoint that express spread rate from a point-source fire as a negative exponential function of time [41, 42]. Parameters of these equations were fit to empirical data from wind tunnel experiments by [43]. These functions asymptote toward a final equilibrium rate and are, thus, commonly communicated in terms of the time to reach some fixed fraction of equilibrium (e.g., 90\%). A similar result was developed by Weber [44] which represented acceleration of fires expanding as a circle from a point ignition and depended on the curvature of the fire front.

Studies of acceleration typically report time elapsed from ignition to a near-steady spread rate. Values of 20-30 minutes for point-source ignitions in slash fuels for prescribed fire conditions [45] and in pine litter and feather moss [46] have been reported. Wind-driven grass fires in Australia [47] showed large variation in acceleration times (about 6 minutes under slow wind conditions to over 45 minutes with faster winds) and a strong dependency on the width of the fire front. Wind tunnel burns of shallow ( $8 \mathrm{~cm}$ deep) pine needle and excelsior beds suggested time to equilibrium of only a few minutes [43] and largely independent of windspeed. Data from point-ignitions in pine needle litter reported by Curry and Fons [48] suggested wind speed affected acceleration rate (increased time to equilibrium) as well as a final spread rate. Wind speed may also affect acceleration times for conflagrations involving structures at urban densities. Chandler et al. [49] referenced much longer time estimates than wildland fuels, including 1 hour to achieve near-steady spread rates with wind speed up to $6.7 \mathrm{~m} / \mathrm{s}, 2 \mathrm{hrs}$ for winds to $17.9 \mathrm{~m} / \mathrm{s}$ and possibly much longer times for stronger winds. A long acceleration period, exceeding the 36 minute observation time, was described for line ignitions in heavy fuel loadings associated with felled eucalyptus slash [50]. By contrast, rapid acceleration to near-steady burning after line ignition was reported for experimental crown fires in jack pine forests [51]. Implications of a theoretical analysis by Albini [47] suggests that line ignitions in surface fuels could accelerate very rapidly, initially overshooting the steady rate, but slow and 
exhibit damped oscillations toward the steady value as the increasing vertical buoyancy of the combustion zone offsets horizontal wind force. From the existing literature, it is not clear what influences the various factors of fuel loading, fuel sizes or burning duration, and final spread rates have on acceleration time, nor more complicated interactions among multiple flame zones or heat sources.

It should be mentioned that acceleration of fires can also occur when air inflow is asymmetrically restricted by surface topography, either in canyons [52] or inclined channels [53] and slopes [54, 55]. Detailed treatment of these important fire-topographic interactions, however, is beyond the scope of this paper of fire-fire interactions.

2.2. Length of Fire Front. Fire acceleration and final spread rate appear to be dependent on fire size. Fires accelerate slowly from point-ignition sources $[43,45,56]$ relative to line-source ignitions $[35,56]$. At the small scale of laboratory stick arrays, fuel bed width and proportion of edge on the curvature of the head fire had significant effects on spread rate [57]. In wind driven grass fires, fire spread rates were found to be dependent on the length of the ignition for lines shorter than 50-75 $\mathrm{m}$ [56] and required longer acceleration times for higher winds (Figure 4). Experiments and modeling by Wotton et al. [58] for fires in red pine litter, however, showed no increase in radiation from flames for ignition lines longer than about $2 \mathrm{~m}$ and no effect of line width on spread rate beyond about $1 \mathrm{~m}$. Dold et al. [59] offered an explanation for fire size effect on forward spread rate. As fires expand in two dimensions, the distance between the fire edges increases, meaning that buoyancyinduced inflow along segments of flaming front comes from a wider area. This allows ambient winds from behind the front to penetrate to the heading portion of the flame zone. Such effects on narrow combustion zones of expanding fires are presumably different than for mass-fires or large-area ignitions which create indrafts from all directions $[60,61]$ and strong buoyancy-driven convection may deflect ambient air-flow around the column [3].

2.3. Flame Tilt. Flame angle orientation relative to the unburned fuel is related to acceleration and is affected by fire size and stage of growth. Flames can tilt due to wind, slope, or the interaction with other fires. Flames tilted away from the direction of spread are referred to as backing fires, and flames tilting toward the direction of spread are referred to as heading fires. Flames tilt toward the interior of the burned area in small fires or point-source fires, producing backing spread [37, 57, 62]. Spread rate of backing fires spreading downslope has been shown to be only weakly diminished as slope increases [63] and little affected by wind $[43,64]$. Backing fires have been reported to increase fuel consumption and residence times. As fires grow larger, backing fire remains only at the rear of the perimeter (upwind or downslope) and flames for the heading portion of the fire tilt toward the unburned fuel. The very large differences in spread rate and intensity between backing and heading fires (and flanking fires) can be estimated assuming elliptical fire shapes [65]. Numerous studies of flame tilt angle in wildland

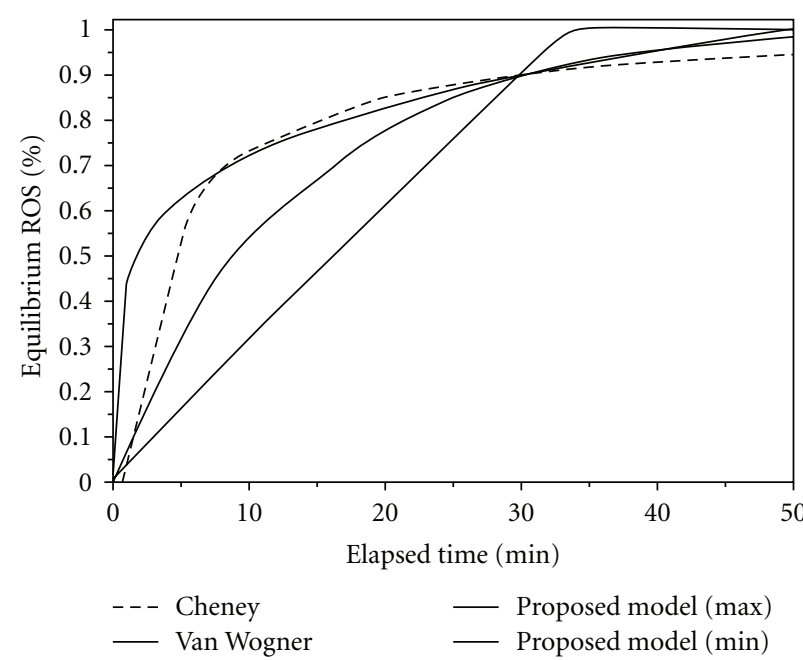

Figure 3: Theoretical fire spread rate acceleration curves from point-source ignitions show asymptotic increase in spread rate over time toward an equilibrium rate (from [43]).

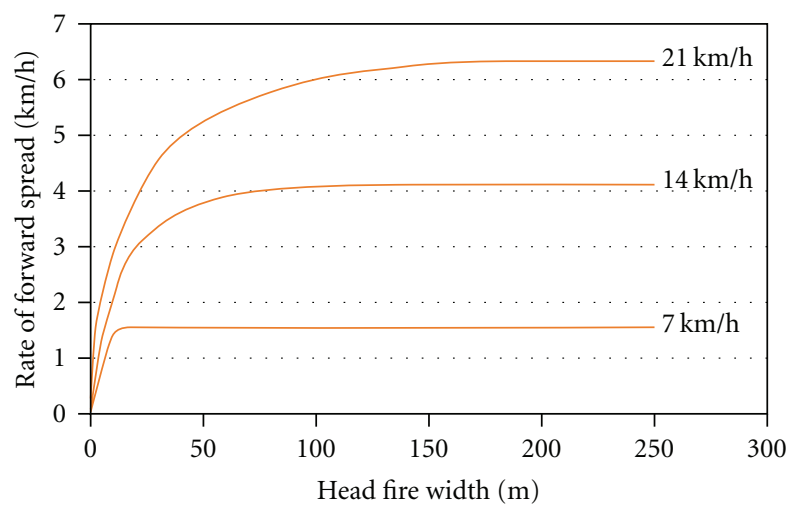

FIGURE 4: Fire spread rates in grass fuels were found to increase with the width of head fires and depend on the final spread rates determined by wind speed [62].

fuel bed on flat terrain in wind have consistently found a strong relationship to the Froude number calculated from ratios of wind speed to intensity or flame length [47, 6668]. Similar experimental results were found using liquid pool fires [69-72] and explained as the counteraction of upward buoyant forces by cross flow, including flame trailing (lateral deflection of combustion products and flames) with high wind speeds. Recent numerical modeling [73] has also reported Froude number relationships for both line-source and point-source simulated fires. Although slope effects were deemed significant [68], they are not accounted for in such formulations. When fires are in close proximity, the interaction between them can change the flame tilt angle and rates of spread $[5,74,75]$. In these cases, the flame tilt angles can be correlated with a modified Froude number that includes the separation distance of the fires $[5,74,75]$. In the case of no wind, a modified Grashof number is used [76, 77] to describe the flame tilt purely due to flame interaction. 
2.4. Spread Thresholds. Thresholds describe a point of nearinstantaneous acceleration that delineates when fire will and will not spread. Threshold-crossing for fire spread has been documented for many discontinuous fuel types including grasses [78], shrubs [79-82], and trees [83, 84]. Laboratory scale fires reveal similar spread thresholds in arrays of small sticks [85-87] and taller beds of excelsior [88]. These studies reveal threshold dependencies on multiple environmental, fuel, and fire variables, such as wind speed, fuel moisture, slope, horizontal fuel gap dimensions, fuel bed depth, fuel combustion rate, and flame size. Chandler et al. [49] proposed combinations of ranges of wind speed, humidity, and rainfall by fuel type to define spread thresholds for significant growth of large fires. Recent studies of fire spread sustainability provide empirical evidence on the importance of fuel moisture, wind, and fuel loading [89, 90]. As described in later sections of this chapter, fireinteractions exert strong influences over many of these same environmental and fire variables, and thus, may elicit threshold-crossing spread for fires burning in discontinuous fuels.

\section{Conditions where Fire Interactions Occur}

Interactions are possible when many separate fires grow together or multiple segments of a single continuous fire are oriented in close proximity. In natural wildland fires, multiple fronts often occur because of spotting from a single main fire. Spot fires are relatively common under dry and windy conditions and even long-distance spotting contributes to fire movement [91]. But, massive deposition of firebrands at relatively short distances from the fire front (a few kilometers) can substantially increase spread rate and create simultaneous area ignition [41]. On wildfires Cheney and Bary observed the highest concentration of fire brands fell within a fan-shaped zone about 9 degrees in angle on either side of the primary wind direction and theorized that mass fire behavior could be achieved for certain unspecified combinations of fire brand density and acceleration time for individual ignitions. Johansen [38] made similar observations for spot ignition patterns on prescribed burns where higher spot densities increased the numbers and frequencies of junction or merger zones. The increase in intensity at such junction zones have been documented empirically [38, 92] and modeled [93] leading to recommendations for wide separation of ignitions $[62,94]$ unless area ignition is desired [95]. Mass ember deposition and area ignition has been documented by McArthur [96] for Tasmanian fires which resulted in near-simultaneous ignition of hillsides. A similar process was proposed for the Air Force Bomb Range Fire [97] which periodically caused area ignition ahead of the main front and vertical development of a convection column. Modeling by Weihs and Small [98] showed that interactions between large mass fires can even cause these typically nonspreading fires to propagate toward one another.

How close together fires must be before flames visibly interact and subsequently merge is not clear. There have been many empirically derived merging criteria in the literature.
Correlations exist for the critical parameters for both flame interaction [99-101] and merging [24, 102-104]. These correlations take many forms-some define a critical ratio between the fire spacing and fire diameter $[24,100]$ or flame height [99, 101, 104], some define a critical ratio between the flame height and fire diameter [24], and some define a critical dimensionless heat release rate $[102,103]$. Upon close examination, however, it becomes clear that fire spacing, fire diameter, flame height, and dimensionless heat release rate have interdependencies and, thus, these different correlations are not necessarily contradictory. The discussion here will focus on the relations between spacing, diameter, and flame height because they are the most intuitive.

Using both gas diffusion burners and pool fires, Sugawa and Takahashi [100] report that flames begin to interact when the ratio of the spacing distance to the fire diameter is less than four. In other words, flames can interact, here defined as visually tilting, over distances four times their diameter. Baldwin [99] considered the onset of flame interaction in terms of flame height. Flames were considered to be interacting if the flame heights increased more than $10 \%$ above the independent flame height. Using square and round gas burners, wood cribs, and large timber yard fires Baldwin [99] (and [105-107]) correlated experimental data over a wide range of scales and configurations found in the literature and determined that the flames would interact if the spacing was less than 0.22 times the flame length. For a characteristic dimension $D$ and height $L$, this correlation holds for $1<L / D<300$. Liu et al. [101] also found the same dependency but with a slightly different constant of proportionality for merging of round pool fires. In their experiments, flame merging was likely to occur when closer than 0.29 to 0.34 times the merged flame length. Delichatsios [104] also found that flames began to merge at spacing less than 0.33 times the actual flame length for gaseous burners. The discrepancy in these constants may be due to different definitions of flame interaction (tilting versus change in flame height) and flame merging (using completely merged flame height versus actual flame height), different fuels, and possibly uncertainty of measuring flame dimensions. In comparing the results of the Project Flambeau fires to those using a sand-filled pan burner, Wood et al. [24] reported that flames merged if the flame height was at least half of the fire diameter. Heskestad [6] clarified that this occurs when the nondimensional group $N \sim Q^{2} / D^{5}$ is near $10^{-5}$ ( $Q$ is the heat release rate and $D$ is the fire diameter). Clearly there is no definitive criterion for when flames begin to interact and merge, and these relations will remain qualitative guidelines until there is some sort of unifying theory.

An opposing effect may occur with area fires over large homogenous fuel beds (small flame height compared to fire diameter). For a sufficiently large fuel bed, it may be impossible for a continuous flame to exist over the entire bed. Instead of one continuous flame, the fire may break up into many distributed flamelets $[13,24,108]$. Heskestad [108] showed that the breakup of continuous flames occurs when the nondimensional group $N \sim Q^{2} / D^{5}$ is near $10^{-6}$. The convection column for these cases has been described as having two modes: Bénard cell convection near the surface 
which merges and transitions to a more organized convective plume [109].

\section{Specific Effects of Fire Interaction}

Studies of fire interactions involve specific types of behavior of the combustion and observable fire characteristics. Most of the research on these behaviors comes from laboratory experiments with artificial fuel sources and attempt to isolate the particular response of interest.

4.1. Burning Rate. When fire fronts are close enough to interact and merge, such as in a mass fire, the mass of fuel burned as a function of time, or burning rate, of the fire can change dramatically. Though much of the research on fire interactions has been done using gas burners with a fixed burning rate, there has been some work on the interaction of flames over liquid pool fires and wood crib fires. Though the geometry and heat transfer mechanisms inside the fuel bed are different, liquid pool fires are much like fires burning over solid fuel in that the heat transfer from the fire back to the fuel controls the burning rate. In contrast, the burning rate of a gas burner is controlled by using a fixed fuel supply rate. Results from pool and crib fire experiments can often be extended to larger fuel beds using appropriate scaling laws [110].

The experiments by Huffman et al. [111] clearly reveal the effect of spacing on the burning rate of pool fires. In this work, the burning rate of an array of liquid pools was measured while keeping a constant fuel depth and varying the number of pools, pool diameter, fuel, and pool separation distance. In general, the burning rate of each individual pool burner increases as the burners are brought closer together and the flames began to interact. In particular, the pools in the middle of the array show a very dramatic increase. For example, Figure 5 shows that the burning rate of 4 inch diameter pools of cyclohexane experienced over a $400 \%$ increase in burning rate when the separation distance was halved. At the onset of flame merging, the burning rate is at its maximum. As the flames merge, the burning rate decreases as the separation distance continues to decrease. In the limit of zero separation distance, however, the burning rate of the individual fires is still larger than if they were burning independently with no interaction effects. These trends were also seen by Grumer and Strasser [112] with solid fuel beds.

Kamikawa et al. [113] studied the effect of flame merging on heat release rates (heat released per time). Heat release rate is calculated by multiplying the burning rate (mass of fuel burned per time) by the heat of reaction (heat released per mass of fuel burned). However, the heat of reaction is dependent on the fuel and the mixture ratio of fuel to air. In large fire arrays, the inner regions of the array typically experience a shortage of air. Without sufficient air, the fuel cannot completely react and release the full potential heat, that is, the combustion efficiency is low and less heat is released per mass of fuel. Not surprisingly, Kamikawa et al. [113] saw the same trend with heat release rates as Huffman et al. [111] with burning rates. When the flames are merged, the heat release rate increases with separation distance. As the burners are moved further apart, more air can penetrate into the inner regions of the array. More air entrainment means greater combustion efficiency and greater heat release. This in turn heats up and evaporates the unburned fuel more quickly, increasing the burning rate.

Liu et al. [114] explain the mechanisms behind these trends in burning and heat release rate with separation distance. The nonmonotonic behavior seen in Figure 5 is the result of two competing mechanisms: heat feedback enhancement and air entrainment restriction. As the burners are moved closer, the view factor between neighboring fires increases. In other words, the fires can "see" each other better, increasing the radiative heat transfer in addition to the convective heat transfer [112]. Because the burning rate is dictated by the heat feedback from the flame, this increased radiative heat seen by the fuel will evaporate the fuel more quickly and increase the burning rate. Conversely, as the fires get sufficiently close there is less room to entrain air inside the array and the flames become "choked." When the flames are merely interacting, the heat feedback mechanism is more important than the air restriction and the burning rate increases. When the flames have merged, the air restriction is the dominant mechanism and the burning rate decreases.

Because the experiments by Kamikawa et al. [113] used wood crib fires, they were also able to examine the release rate as a function of time for merged flames. As with most wildland fires, the heat release rate (and burning rate) of wood crib fires increases as the fire builds, reaches a maximum, then begins to decrease as the fuel is depleted. Kamikawa et al. [113] made the observation that as the number of fires increases, the peak heat release rate increases above that expected by multiplying the independent fire heat release rate by the number of fires. This discrepancy grows as the number of fires increases. So the burning and heat release rates of interacting and merging fires not only are dependent on the spacing of the fires, but also on the total number of fires (see also [114]).

Fire interactions can increase burning rates by another mode as well. If the fires interact such that vorticity is generated, fire whirls can form. Though not discussed further here, it has been shown that fire whirls have dramatically increased burning rates in comparison to an equivalent, nonrotating fire (see, e.g., $[115,116])$.

4.2. Flame Dimensions. Flame height trends for a nonpremixed flame, such as those in a wildfire, are usually discussed in terms of two dimensionless parameters: the dimensionless flame height and the dimensionless heat release rate. The dimensionless flame height is usually defined as the flame height divided by the characteristic burning area diameter $(D)$. The characteristic burning area diameter is a dimensioned parameter frequently introduced in fire arrays and is usually some function of the number of fires, fire diameter, and the fire arrangement (separation distance). The dimensionless heat release rate $\left(Q^{*}\right)$ is usually defined as the total heat release rate of the group divided by the characteristic burning area diameter to the five-halves power (material property constants are used to make the 


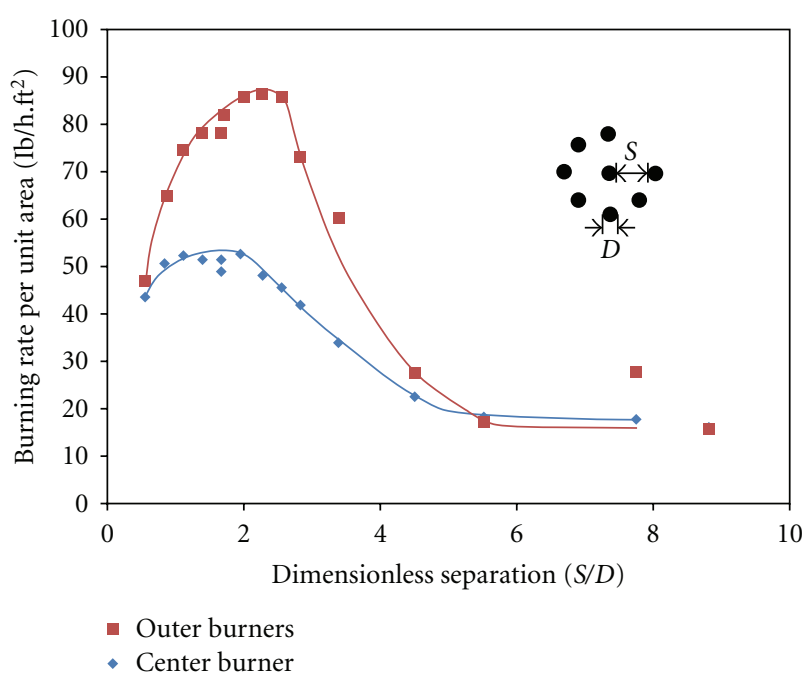

Figure 5: Burning rate as a function of separation distance for $10.1 \mathrm{~cm}$ diameter cyclohexane burners from [111].

ratio dimensionless: $\left.Q^{*} \sim Q_{\text {tot }} / D^{5 / 2}\right)$. The dimensionless heat release rate for natural fires tends to fall between 0.05 and 5 [117].

Much of the research on flame height has been performed using gas burners. However, two regimes of flow from a gas burner can be identified. When the flow velocity is low or the burner diameter is large, the momentum of the gaseous fuel is due primarily to its buoyancy. When the flow velocity is high or the burner diameter is small, the flow is like a jet. Putnam and Speich [102] have a method for determining whether the flow from a gas burner is a high momentum jet or buoyancy controlled. The discussion here will be limited to turbulent, buoyancy-driven flames, as this situation better describes what occurs during a wildfire.

In general, the flame height increases as the fires are moved closer. When the flames begin to merge, the flame height will dramatically increase with further changes in separation distance. However, once the flames are fully merged, further decreases in separation distance will have little effect $[102,103,119]$. The dimensionless flame height has successfully been correlated to the dimensionless heat release rate raised to some power $a$. Because the dimensionless heat release rate can vary over at least seven orders of magnitude, this power " $a$ " can take on three different values depending on the range of the dimensionless heat release rate. As shown in Figure 6 [118], the dimensionless flame height increases with the dimensionless heat release rate. These correlations were originally developed for the flame height of a single independent burner where the characteristic dimension is the burner diameter, and hold for buoyancy-driven gas burners, liquid pool fires, and wood crib fires. However, there is an indication that these correlations also apply to interacting flames when the characteristic burning area dimension is given as discussed above. For example, for the interaction of relatively tall flames compared to the actual burner diameter $\left(L_{f} / D>1\right.$, or high values of $\left.Q^{*}\right)$, Putnam and Speich [102] and Sugawa and Takahashi [100] showed that the dimensionless flame height correlates well with the dimensionless heat release rate to the two-fifths power $\left(L_{f} / D \sim Q^{* 2 / 5}\right)$. Delichatsios [104] successfully correlated the dimensionless flame height to the dimensionless heat release rate to the two thirds power $\left(L_{f} / D \sim Q^{* 2 / 3}\right)$ for $Q^{*}$ between 0.1 and 1. On the other hand, Weng et al. [120] and Kamikawa et al. [113] showed that the data for merged flame height is better correlated with the exponent " $a$ " varying with the number of burners.

With all else remaining constant, these correlations suggest that an increase in either the number of fires or the individual fire heat release rate will increase the interacting or merged flame height. Increases in the separation distance or the fire diameter will result in a decrease in the interacting or merged flame height. An interesting caveat to these correlations is that the burning rate for individual pool or crib fires is not constant, but is a function of the separation distance as discussed above. This trend is not necessarily captured in Figure 6 or by Putnam and Speich [102] (gas burners), Kamikawa et al. [113], Fukuda et al. [103], or Delichatsios [104] (all fully merged flames). Also, vorticity can greatly increase flame height as well [115].

This literature suggests that in a mass fire situation, as the flames grow closer together, the heat release rate and characteristic "burner" diameter should increase. The net effect is most likely an increase in the flame height. If more spot fires were ignited in the burning area, for example, the flame height would increase further. This is consistent with the observations of spot ignitions on prescribed burns [38] and mass spotting in wildfires [41]. However, for a sufficiently large area or mass fire, when the nondimensional group $N \sim Q^{2} / D^{5}$ is near $10^{-6}$, the fire is not expected to burn as a continuous flame but will break up into many distributed flamelets $[13,24,108]$. In this case, the flame height will be less than that predicted for a fully-merged, continuous flame but larger than that of isolated flames [121].

4.3. Flame Temperatures and Pollutants. As discussed in relation to flame height, as fires are moved closer together, air entrainment is blocked and the gaseous fuel must travel higher to find sufficient air for combustion. Experiments by Chigier and Apak [119] indicated that a fuel particle on its journey from the base to the tip of an interacting turbulent flame would experience delayed combustion compared to an independent flame (see Figure 7(a)). The delay means that the maximum temperature of the interacting flames would occur further from the flame base. With limited mixing of fresh air into the flame to provide cooling, the temperatures inside an interacting flame decay more slowly with height so the flame is hot over a greater portion. In addition, limited mixing of air into the flames causes the formation of more carbon monoxide inside the flame zone. This prompted Countryman [13] to speculate that the lack of oxygen in conjunction with elevated carbon monoxide could be fatal to ground personnel trapped inside the burning area.

Chigier and Apak [119] also showed that the maximum temperature achieved by interacting turbulent flames is also a function of the separation distance and the number of burners (see Figure 7(b)). When the flames are close 


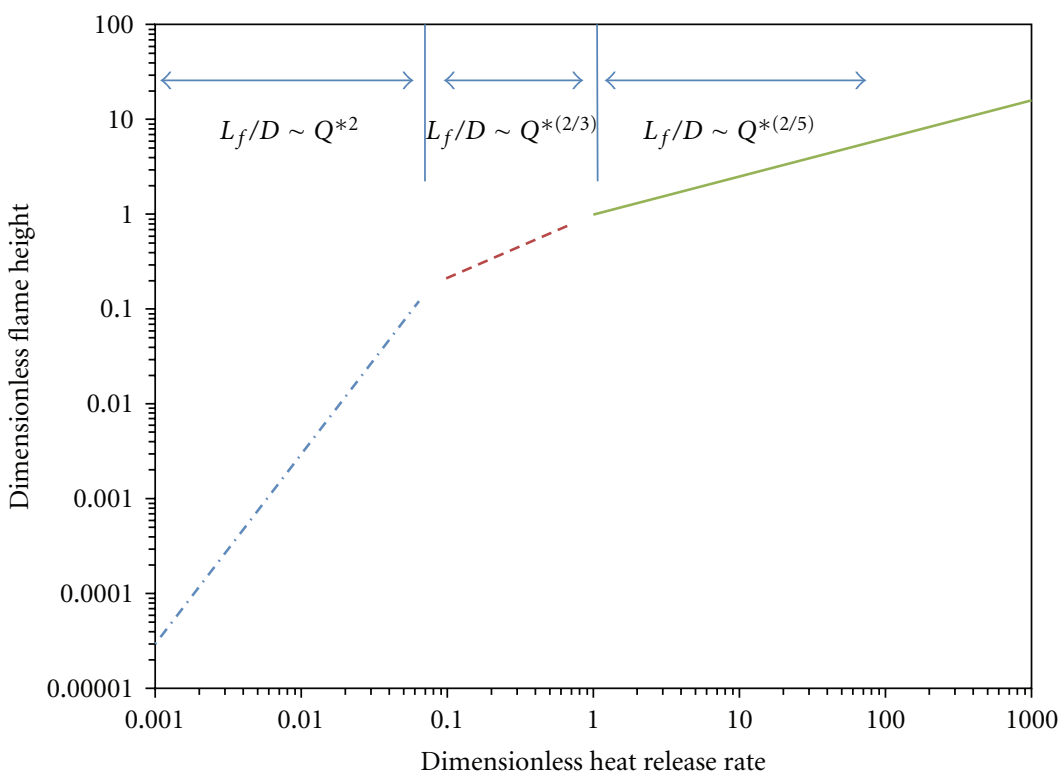

FIGURE 6: Dimensionless flame height $\left(L_{f} / D\right)$ correlations with dimensionless heat release rate $\left(Q^{*}\right)[118]$.

enough to interact, they lose less heat from radiation (the surroundings are at the same temperature) and by mixing with cool, fresh air. The maximum temperatures inside interacting flames therefore increase as the number of fires increases and as the burners get closer together. These increased temperatures could produce more of the smogforming nitrogen oxide emissions [122].

4.4. Indraft Velocity. In typical fire situations where the flame height is relatively tall compared to the fire diameter, standard correlations exist to predict the mass of air entrained by the fire and its plume due to the velocity difference between the plume gases and the ambient air. This air entrainment causes an inflow into the fire and is generally responsible for the bending of two flames in relatively close proximity. However, the standard correlations of plume theory are valid only above the flame. Though several plume theories exist in the literature (see paper in [123]), there is general agreement that the total mass of air entrained can be estimated as proportional to the convective heat release rate (heat release rate minus radiative and other losses) raised to the onethird power and to the height above the fire source to the five-thirds power. Fires with greater heat release rate entrain more air and the total amount of air entrained increases with height above the plume. Note, however, that the velocity of the flow inside the plume decreases with height, so at some point near the top of the plume no further air is entrained (no velocity difference). Current research on the indraft caused by entrainment as related to fire interactions is focused mainly providing better quantitative predictions with CFD modeling [93, 124].

However, plumes from wildfires can interact with local meteorology [125] such as wind and atmospheric conditions. Additionally, classic plume theory for entrainment rates may not hold for small ratios of the flame height to fire diameter
$\left(L_{f} / D\right)$. Though the exact threshold is not known, Heskestad [123] contends that the standard plume theory falls apart for $L_{f} / D$ somewhere between 0.14 to 0.9 . The perimeter of the plume where entrainment occurs becomes too small in relation to the volume of air inside and the slow moving entrained air will not have much effect on the momentum of the entire plume. Mass fires by definition fall into the range of flame height to fire diameter ratios where classic plume theory does not hold. The results of the Project Flambeau burns confirm that there is little entrainment into the plume core [126]. Many authors (e.g., [30, 60, 127]) also argue that the entrainment of plume theory does not account for the reported high velocity winds associated with mass fires. As discussed earlier, mass fires are characterized by such strong indrafts that the fire does little outward propagation. In their paper of the range of possible indraft velocities, Trelles and Pagni [128] showed that indraft velocities of large fires can range from about 2 to $40 \mathrm{~m} / \mathrm{s}$. In the Project Flambeau burns, Countryman $[3,12,13]$ also reports complicated airflow patterns and strong downdrafts which cannot be accounted for with simple plume theory.

There seem to be two main theories in the literature as to what causes the high velocity inflows. One theory, advanced by Baum and McCaffrey [61] and Carrier et al. [7] is that large-scale vorticity in conjunction with heat release is responsible. These models contend that the entire fire plume slowly rotates. Note, however, that Church et al. [129] and McRae and Flannigan [130] characterize this type of motion as one type of fire whirl. In Baum and McCaffrey's model (also used by $[128,131]$ ), this rotation is caused by density gradients from the high heat release, and not necessarily by any imposed swirling caused by the ambient environment. The slow rotation of such a large mass of air above the ground translates to high velocity, purely horizontal and nonrotating flow at the ground. 


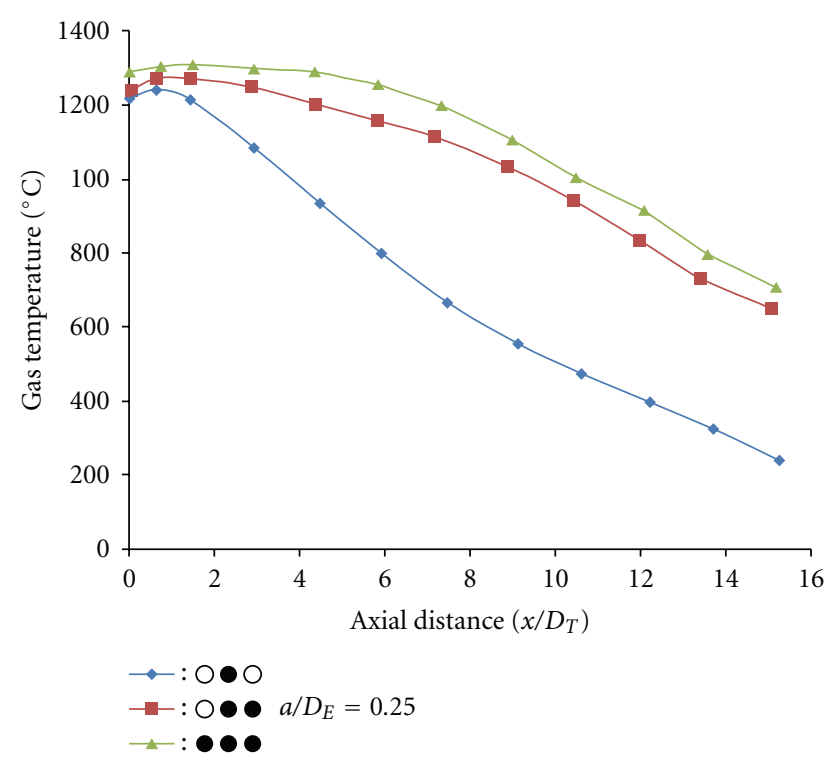

(a)

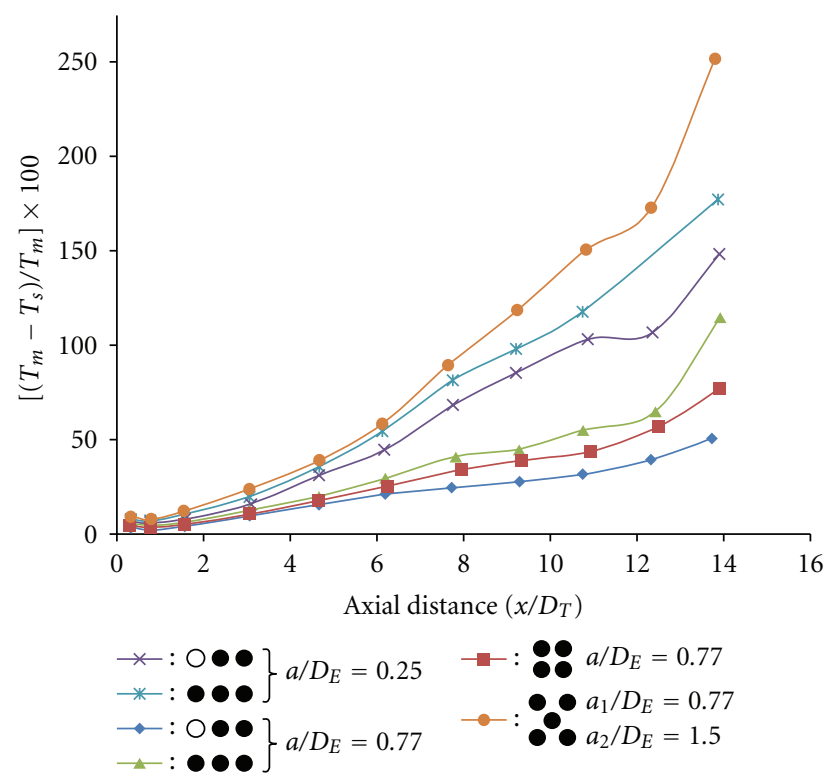

(b)

Figure 7: (a) Effect of nearby burners on flame temperature from [119]. $D_{T}$ is throat diameter, $D_{E}$ is exit diameter, $a$ is separation distance, $T_{m}$ is merged flame temperature, and $T_{s}$ is single flame temperature. (b) Temperature compared to independent flame for varying axial distance along flame, number of burners, burner arrangement, and burner spacing from [119].

One unique feature of the Baum and McCaffrey model is that it treats the large area fire as an ensemble of randomly distributed individual fires of varying strengths. Because of the method chosen to represent the fire, the model is only valid for heights above the fuel bed where the plumes of the individual fires have not merged. The model of Carrier et al. [7] was intended to determine how long it would take to spin up the convective column and under what conditions this occurred. Based on the fact that the fire in Hamburg,
Germany took two hours to develop, they concluded that the growth of swirl, at least in this case, was most likely due to the intensification of a preexisting vortex from earlier fires and bombings. Though this contradicts the Baum and McCaffrey model, the experiments and discussion by Church et al. [129] support this argument. The spatial orientation of individual fires may cause a swirling flow due to the interaction of the indrafts to each fire [132]. Carrier et al. [7] found that large diameter plumes spin up faster and proposed a set of four criteria that must be met for a "firestorm" to develop: heat release of $10^{6} \mathrm{MW}$ over a localized area for two to three hours, a preexisting weak vortex, low ambient winds, and a nearly dry-adiabatic lapse rate over the first few kilometers of the atmosphere.

Because it seems unlikely that all the criteria for spin up of a convective column will be met, another theory, advanced by Smith et al. [60] and Small et al. [30] is proposed. These authors claim that buoyancy-induced pressure gradients are responsible for the large indrafts. Smith et al. [60] used a simple two-dimensional model of a convective column over a hot area to effectively show that near the fire a dynamic pressure gradient can cause high velocity inflow. This dynamic pressure gradient is caused by a balance between hydrostatic pressure and buoyancy. Buoyancy pushes the hot gases up while atmospheric pressure pushes fresh air at the ground in toward the fire horizontally to fill the gap left by the rising gases. Smith et al. [60] also suggest that the traditional "weakly buoyant" plume theories described above may be valid for a small range of plume heights sufficiently far away from the fire and any inversion layer above. Small et al. [30] use a similar model to Smith et al. [60] but include a volume heat addition and large density and temperature gradients. Small et al. [30] also numerically match their model results of the area near the fire to the results of traditional plume theory for the region far from the fire. In both the Smith et al. [60] and Small et al. [30] models, the fire is treated as a single large heat source (Figure 8). Small et al. [30] used their model to demonstrate how the maximum indraft velocity varies with fire radius, burning rate, and fire height (Figure 8 ). They showed that the maximum indraft velocity at first increases but eventually levels off (to approximately $40 \mathrm{~m} / \mathrm{s}$ ) with increases in both the fire radius and the burning rate. On the other hand, the maximum indraft velocity appears to be linear with fire height.

A third, yet not well-explored explanation is proposed by Carrier et al. [134]. In this work, they use classic plume theory, but assume that the fire does not burn as a single fire, but a collection of individual fires. They hypothesize that the high indraft velocities are then due to the increased fire perimeter from this "multicellular burning zone." This hypothesis was not further developed and in later works, these authors treated the fire as a subterranean point source. Interestingly, both the Baum and McCaffrey [61] and Small et al. [30] models reasonably replicate what little experimental data is available. However, the theories differ slightly in their predictions of the distance away from the fire that these indrafts extend [5]. The model of Baum and McCaffrey [61] predicts that the high velocity indrafts will 


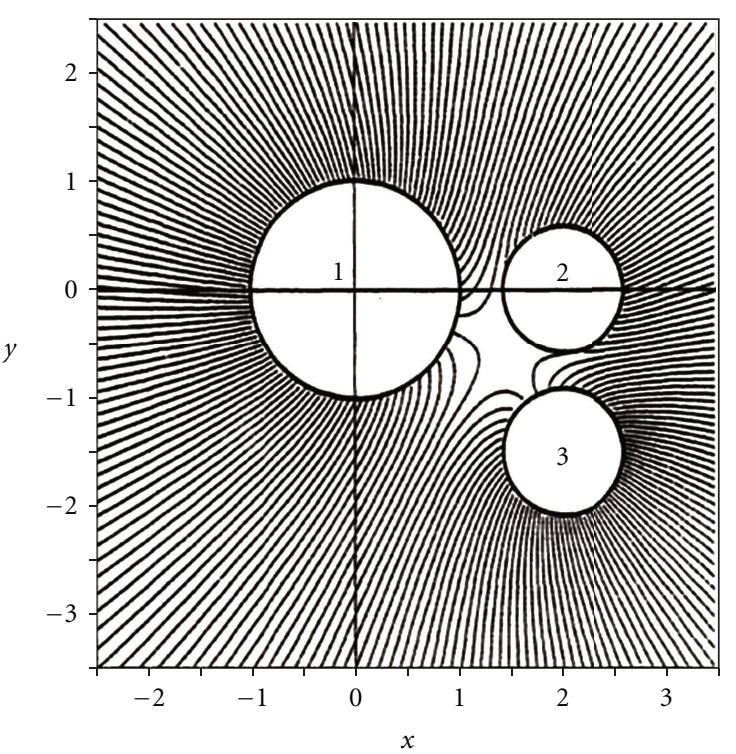

(a)

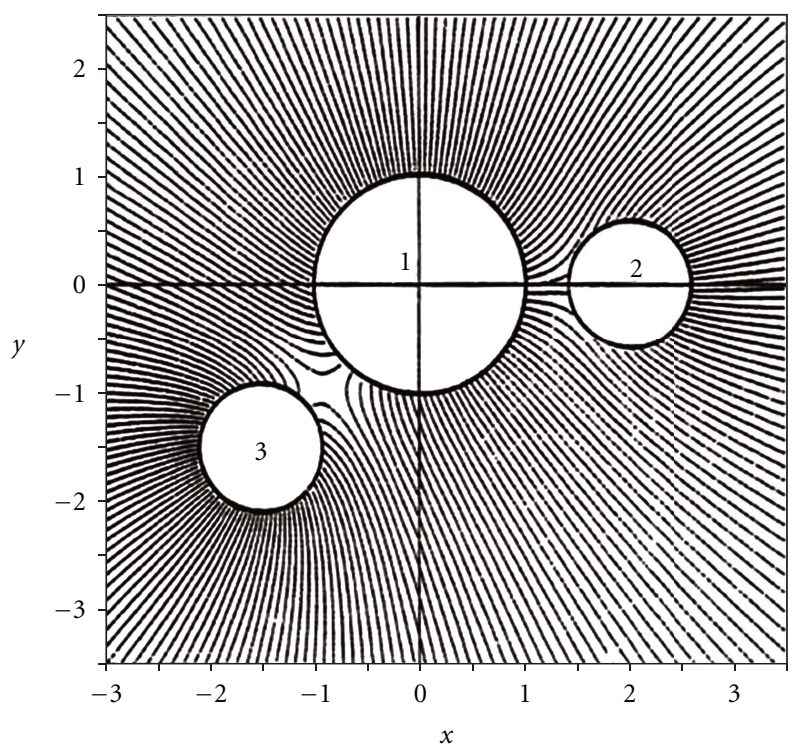

(b)

FIGURE 8: Model results for flow-field streamlines for three fires in close proximity (from [98]).

extend much further from the fire compared to the model of Small et al. [30]. Without more detailed experimental data, it is impossible to say which model is more accurately portraying the physics.

4.5. Pulsation. Though not an effect of flame interactions, flame pulsation (or puffing) is an interesting phenomenon that can occur in stationary fires, such as a mass fire. This pulsation typically occurs in circular or axisymmetric fires in weak ambient wind and is periodic in nature. Flame pulsation is important to many researchers because it can have a large influence on air entrainment rates and therefore heat release rates and pollution formation [135].

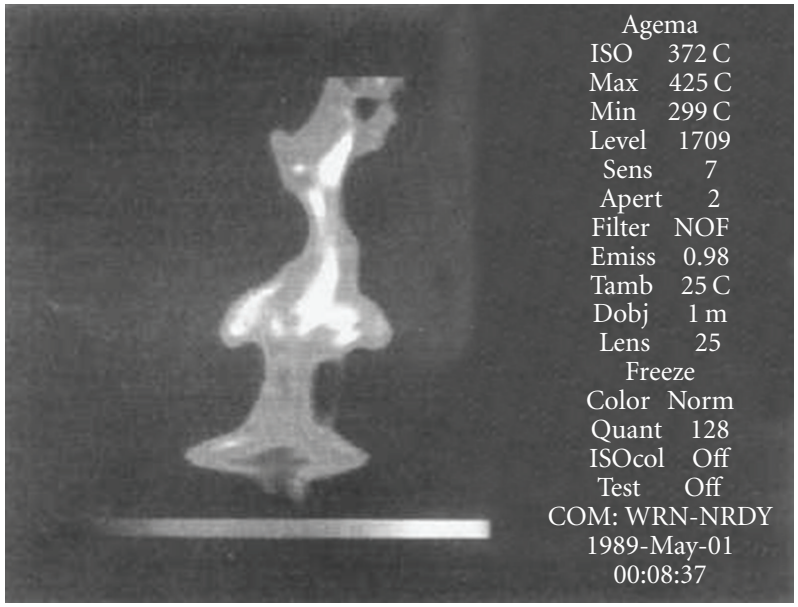

(a)

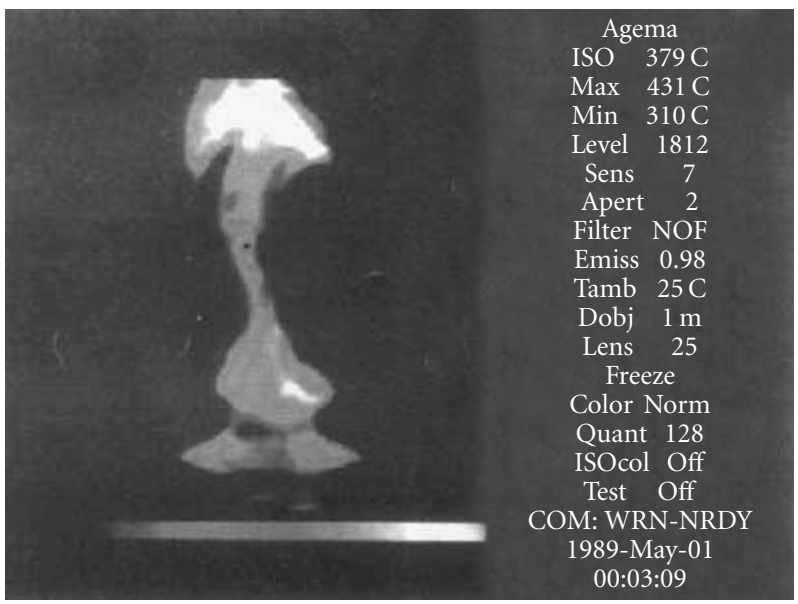

(b)

FIGURE 9: Thermal images of flame pulsation from [133].

Observations of this phenomenon reveal the expansion of the flame near the base of the fire as a toroidal vortex, about the size of the fire diameter. As this vortex is shed and propagates upward, the flame necks inward giving the appearance of a "mushroom" shape. Figure 9 illustrates the process with time sequence of photos. Not all circular flames pulsate, however. Using dimensional analysis, Byram and Nelson [136] attempt to describe what type of fires will pulsate. They define a dimensionless "buoyancy" number, $\pi_{2}=\dot{Q}_{c} /(g D)^{0.5} \rho c_{p} T$, where $\dot{Q}_{c}$ is the rate of convective heat release per area, $D$ is the fire diameter, and $\rho, c_{p}$, and $T$ are the density, specific heat and temperature of the ambient air. Though no quantitative values are given, they argue that a fire will not pulsate if $\pi_{2}$ is either too small (low heat release rate relative to large fire diameter) or too large (large heat release rate relative to small fire diameter).

Because this puffing occurs in nonreacting helium plumes, it is actually not caused by a combustion instability, but instead is produced by a fluid dynamic instability [137]. Though there is disagreement about the actual cause of the instability [138], the vortex is generally thought to be formed 
because of the interaction between gravity and the density gradient between the flame and ambient [135].

Most of what has been learned about the characteristics of pulsation has been learned through experiments. Cetegen and Ahmed [137] showed that the toroidal vortex forms within one fire diameter above the flame base and that the frequency of the puffing is insensitive to the fuel or the heat release rate. By plotting the available data in the literature, Cetegen and Ahmed, and later Malalasekera et al. [133], showed that the pulsation frequency is proportional to the fire diameter raised to the negative one-half power $(f \sim$ $D^{-1 / 2}$ ) so that large fires pulsate at a much lower frequency than small fires. Though this correlation was developed using data from fires ranging from $0.1 \mathrm{~m}$ to $100 \mathrm{~m}$ in diameter (four orders of magnitude) using gaseous, liquid and solid fuels, Baum and McCaffrey [61] suggest that it may well hold for much larger fires as well. For a large fire with a diameter on the order of $20 \mathrm{~km}$, Larson et al. [27] estimate that the pulsation will occur every 20 minutes. Though not accounted for in the above correlation, Malalasekera et al. [133] show that increasing fuel flow rates also result in a small increase in puffing frequency, especially for small fire sizes. Because of this, Malalasekera et al. [133] correlated the puffing frequency in a slightly different manner using the dimensionless Strouhal number (ratio of oscillation frequency to one over the characteristic time of convection) and Froude number (ratio of inertia force to gravitational force) which retains the same dependency on fire diameter but allows for a correction due to changes in fuel flow velocity.

4.6. Convection Column. Mass fires are also described as having very tall convection columns, or smoke plumes with large cloud structures due to the moisture release from combustion [32]. As discussed in the section on indraft velocities, the entrainment of cold, ambient air slows the rise of the hot gases by cooling them. Additionally, the density of the ambient air itself decreases with elevation. As the hot gases rise and cool, the density difference driving their upward motion disappears. It follows then that the top of the smoke plume corresponds to the where the combustion products stop moving. As the fire diameter grows, however, the entrainment predicted by classic plume theory becomes less effective. Entrainment occurs at the perimeter of the plume and with large fire sources there is such as large core of hot gases that entrainment is less effective at slowing the rise of the combustion products [126] (Palmer 1981). Thus, it takes longer to entrain enough cold air to slow the combustion products and therefore the smoke plume becomes taller. For example, a lack of entrainment to the convection column was noted and discussed by Taylor et al. [95] on a large prescribed burn. In fact, the plume from a sufficiently large mass fire may be almost as wide as it is tall, so Brode and Small [31] and Palmer [126] contend that air entrainment is not likely to be a major influence on plume height and that it is the structure of the atmosphere itself that is the limiting factor. The plume of large mass fires is therefore more sensitive to atmospheric gradients, inversion heights, and upper atmosphere crosswinds (see also [33]).
Brode and Small [31] show that the tropopause/stratosphere transition may be what actually caps the smoke plume. Note, these theories contradict the suggestion of Smith et al. [60] that the traditional plume theory holds at some intermediate height above the ground. Perhaps the scale of the fires modeled by Smith et al. [60] was not large enough to see this effect.

Palmer [126] describes the interesting structure of the convection columns that formed during the Project Flambeau tests. In the first few minutes of these large-scale burns, the majority of the gaseous combustion products were contained in a "bubble" near the fire. Once the "bubble" got sufficiently hot, the associated buoyancy was enough to overcome the surface drag forces and the bubble rose. As the bubble rose, a vortex ring would form in a similar manner described above with respect to flame pulsations. Regardless of the atmospheric stability, this vortex ring would rise until it encountered a region of vertical wind shear. The vertical wind shear weakens the vortex enough for the plume to then follow the prevailing horizontal winds. Palmer [126] also notes that the "exterior form of the convection column at a particular altitude was determined by the initial vortex bubble as it passed that altitude." Most of the plumes in these fires began to rotate as a single vertical vortex, as suggested by the Baum and McCaffrey [61] model. This rotation further inhibits entrainment, which would also prevent the use of classic plume models for mass fires [139].

4.7. Summary of Interaction Effects. As the individual spot fires grow together, they will begin to interact. This interaction will increase the burning rates, heat release rates, and flame height until the distance between them reaches a critical level. At the critical separation distance, the flames will begin to merge together and burn with the maximum rate and flame height. As these spot fires continue to grow together, the burning and heat release rates will finally start to decrease but remain at a much elevated level compared to the independent spot fire. The flame height is not expected to change significantly. The more spot fires, the bigger the increase in burning rate and flame height.

\section{Needs for Further Research and Application}

The characteristics of many fire interactions have been examined and reported in the research literature, leaving little doubt that local spread and behavior experienced by wildland fire personnel can be greatly influenced by fire configurations at larger scales. The ignition patterns and "suppression fire" tactics used in firefighting [36, 140] depend on understanding these interactions. However, questions remain about how to extend the findings of fundamental research, to the field-scale for wildland fires and mass fires. In particular, there is no clear method to determine the minimum separation distance between two fires for interaction and merging to occur. The influence of ambient winds or topography on interactions is directly relevant to wildfire management activities and tactics but has not been explored. Large area fires were discussed as an extreme case of fire interactions and often behave 
quite differently than propagating line fires. Just how much area must be ignited to display "mass fire" characteristics is unknown. Even in the Project Flambeau experiments, Countryman [3] argues that even these large fires were not large enough to be considered mass fires. Both Byram [141] and Thomas et al. [142] developed scaling laws in an attempt to answer this question, but many potentially limiting assumptions were made in the development and the laws were not validated. Baldwin and North [15] attempt to quantify the minimum area for urban applications based on city layout and historical fires, but their estimations are admittedly crude. As discussed, there is no consensus in the literature about the convection column dynamics of mass fires and what mechanism is responsible for the reported strong indrafts. These suggestions are merely a starting point, as the subjects of fire interactions and mass fires clearly involve a great deal of physics and require the union of many fields of study.

\section{References}

[1] R. E. Martin and J. D. Dell, "Planning for prescribed burning in the inland northwest," Pacific Northwest Forest and Range Experiment Station GTR-76, 1978.

[2] R. C. Rothermel, "Fire behavior considerations of aerial ignition," in Proceedings of a Workshop on Prescribed Fire by Aerial Ignition, R. W. Mutch, Ed., Intermountain Fire Council, Missoula, Mont, USA, October-November 1984.

[3] C. M. Countryman, "Mass fires and fire behavior," U. S. Forest Service Research Paper PSW-19, Pacific Southwest Forest and Range Experiment Station, 1964.

[4] F. A. Williams, "Urban and wildland fire phenomenology," Progress in Energy and Combustion Science, vol. 8, no. 4, pp. 317-354, 1982.

[5] W. M. Pitts, "Wind effects on fires," Progress in Energy and Combustion Science, vol. 17, no. 2, pp. 83-134, 1991.

[6] G. Heskestad, "Dynamics of the fire plume," Philosophical Transactions of the Royal Society A, vol. 356, no. 1748, pp. 2815-2833, 1998.

[7] G. F. Carrier, F. E. Fendell, and P. S. Feldman, "Firestorms," Journal of Heat Transfer, vol. 107, no. 1, pp. 19-27, 1985.

[8] K. Hewitt, "Place annihilation: area bombing and the fate of urban places," Annals of Association of American Geographers, vol. 73, no. 2, pp. 257-284, 1983.

[9] R. F. Schmalz, "Chapter six, conflagrations: disastrous urban fires," in Natural and Technological Disasters: Causes, Effects and Preventative Measures, S. K. Majumdar, G. S. Forbes, E. W. Miller, and R. F. Schmalz, Eds., pp. 62-74, The Pennsylvania Academy of Science, 1992.

[10] H. J. Nielson, K. Tao, and L. Wolf, "Analysis of convection column above a fire storm," Final Report, Office of Civil Defense OCD-OS-62-82, IIT Research Institute, 1963.

[11] C. C. Chandler, "A study of mass fires and conflagrations," US Forest Service Research Note PSW-N22, 1963.

[12] C. M. Countryman, "Mass fire characteristics in large-scale tests," Fire Technology, vol. 1, no. 4, pp. 303-317, 1965.

[13] C. M. Countryman, "Project Flambeau - an investigation of mass fire (1964-1967) Final Report-Volume 1,” Prepared for Office of Civil Defense under OCD Work Order OCDPS-65-26, Pacific Southwest Forest and Range Experiment Station, USDA Forest Service, 1969.
[14] A. J. Pryor and C. H. Yuill, "Mass fire life hazard," Final Report N228(62479)68665, Southwest Research Institute, Office of Civil Defense Work Unit 2537A, 1966.

[15] R. Baldwin and M. A. North, "The firestorm-its size and importance," Fire Research Note 645, Fire Research Station, Boreham Wood, Hertfordshire, 1967.

[16] T. E. Lommasson, J. A. Keller, and R. G. Kirkpatrick, "Firestorm analysis," Division of Fire Research US Forest Service 13-248, Dikewood Corporation DC-TN-2046-1, 1967.

[17] T. E. Lommasson, R. K. Miller, R. G. Kirkpatrick, and J. A. Keller, "A "firestorm" existence and buildup hypothesis," Defense Atomic Support Agency DASA 01-67-C-0008, Dikewood Corporation DC-FR-1058.0, 1968.

[18] W. J. Parker, "Urban mass fire scaling considerations," US Navel Radiological Defense Laboratory, OCD Work Unit No. 2536F USNRDL-TR-67-150, 1967.

[19] L. A. Eggleston, "Electronic simulation of mass fires," in Spring Technical Meeting of the Central States Section of the Combustion Institute, University of Southern California, Los Angeles, Calif, USA, 1968.

[20] D. German, "Mass fire infrared measurements," Tech. Rep. D3-7655, Boeing Company, Wichita, Kan, USA, 1968.

[21] B. T. Lee, "Mass fire scaling with small electrically heated models," in Spring Technical Meeting of the Central States Section of the Combustion Institute, University of Minnesota, 1969.

[22] B. T. Lee, "Mass fire scaling with small electrically heated models," Final Report, Office of Civil Defense DAHC20-67C-0149, Naval Radiological Defense Laboratory NRDL-TR69, 1969.

[23] H. J. Nielson, "Mass fire data analysis," Final report for Defense Atomic Support Agency 2018, IIT Research Institute project J6099, 1970.

[24] B. D. Wood, P. L. Blackshear, and E. G. R. Eckert, "Mass fire model: an experimental study of the heat transfer to liquid fuel burning from a sand-filled pan burner," Combustion Science and Technology, vol. 4, no. 1, pp. 113-129, 1971.

[25] J. C. Sanderlin, J. A. Ball, and G. A. Johanson, "Mass fire model concept," Mission Research Corporation, DNA 5803F, Final Report for Period 8 September 1980-31 May 1981 DNA 001-80-C-0351, 1981.

[26] R. D. Small, D. A. Larson, and H. L. Brode, "Analysis of large urban fires," PSR Report 1122, Pacifice-Sierra Research Corp., Final Report EMW-C-0309, 1981.

[27] D. A. Larson, H. L. Brode, and R. D. Small, "Time-dependent model of flows generated by large area fires," Tech. Rep. Note 483, Pacific-Sierra Research, Los Angeles, Calif, USA, 1982.

[28] D. A. Larson and R. D. Small, "Analysis of the large urban fire environment, Part I. theory," PSR Report 1210, Pacific-Sierra Research Corp., Final report EMW-C-0747, 1982.

[29] D. A. Larson and R. D. Small, "Analysis of the large urban fire environment, Part II. parametric analysis and model city simulations," PSR Report 1210, Pacific-Sierra Research Corp., Final report EMW-C-0747, 1982.

[30] R. D. Small, D. A. Larson, and H. L. Brode, "Fluid dynamics of large area fires," in Proceedings of the 21st National Heat Transfer Conference, Society of Mechanical Engineers, Seattle, Wash, USA, 1983.

[31] H. L. Brode and R. D. Small, "A review of the physics of large urban fires," in The Medical Implications of War, Institute of Medicine, National Academic Press, 1986. 
[32] R. D. Small and K. E. Heikes, "Early cloud formation by large area fires," Journal of Applied Meteorology, vol. 27, pp. 654663, 1988.

[33] J. E. Penner, L. C. Haselmen, and L. L. Edwards, "Smokeplume distributions above large-scale fires: implications for simulations of 'nuclear winter," Journal of Climate \& Applied Meteorology, vol. 25, no. 10, pp. 1434-1444, 1986.

[34] J. G. Quintiere, “Canadian mass fire experiment, 1989," Journal of Fire Protection Engineering, vol. 5, no. 2, pp. 67-78, 1993.

[35] R. W. Johansen, "Ignition patterns and prescribed fire behavior in southern pine forests," Georgia Forestry Commission Forest Research Paper 72, 1987.

[36] M. Miralles, D. Kraus, D. Molina et al., "Improving suppression fire capacity," in Towards Integrated Fire ManagementOutcomes of the European Project Fire Paradox, J. S. Silva, F. Rego, P. Fernandes, and E. Rigolot, Eds., European Forest Institute Research Report 23, chapter 5.3, pp. 203-215, Joensuu, Finland, 2010.

[37] R. H. Luke and A. G. McArthur, Bushfires in Australia, Australian Government Publishing Service, Canberra, 1978.

[38] R. W. Johansen, "Prescribed burning with spot fires in the Georgia coastal plain," Georgia Forest Research Paper 49, Georgia Forestry Commission, Macon, Ga, USA, 1984.

[39] C. P. Weatherspoon, G. A. Almond, and C. N. Skinner, "Treecentered spot firing-a technique for prescribed burning beneath standing trees," Western Journal of Applied Forestry, vol. 4, no. 1, pp. 29-31, 1989.

[40] R. K. Arnold and C. C. Buck, "Blow-up fires-silviculture or weather problems," Journal of Forestry, pp. 408-411, 1954.

[41] N. P. Cheney and G. A. V. Bary, "The propagation of mass conflagrations in a standing eucalypt forest by the spotting process," in Mass Fire Symposium, Defense Standards Laboratory, Canberra, Australia, 1969.

[42] N. P. Cheney, "Chapter 7, fire behavior," in Fire and the Australian Biota, A. M. Gill, R. H. Groves, and I. R. Noble, Eds., pp. 151-175, Australian Academy of Science, Canberra, Australia, 1981.

[43] R. S. McAlpine and R. H. Wakimoto, "The acceleration of fire from point source to equilibrium spread," Forestry Science, vol. 37, no. 5, pp. 1314-1337, 1991.

[44] R. O. Weber, "Analytical models for fire spread due to radiation," Combustion and Flame, vol. 78, no. 3-4, pp. 398408, 1989.

[45] D. J. McRae, "Point-source fire growth in Jack Pine slash," International Journal of Wildland Fire, vol. 9, no. 1, pp. 6577, 1999.

[46] O. Kuckuk, E. Bilgili, and I. Baysal, "Fire development from a point source in surface fuels of a mature anatolian black pine stand," Turkish Journal of Agriculture and Forestry, vol. 31, no. 4, pp. 263-273, 2007.

[47] F. A. Albini, "Response of free-burning fires to nonsteady wind," Combustion Science and Technology, vol. 29, no. 3-6, pp. 225-241, 1982.

[48] J. R. Curry and W. L. Fons, "Rate of spread of surface fires in the ponderosa pine type of California," Journal of Agriculture Research, vol. 57, no. 2, pp. 39-267, 1938.

[49] C. C. Chandler, T. G. Storey, and C. D. Tangren, "Prediction of fire spread following nuclear explosions," U.S. Forest Service Research Paper PSW- 5, Pacific SW. Forest \& Range Experiment Station, Berkeley, Calif, USA, 1963.
[50] A. G. McArthur, "The behavior of mass fires in felled eucalypt forest originating from a simultaneous grid or line ignition system," in Mass Fire Symposium, Defense Standards Laboratory, Canberra, Australia, 1969, Paper A1.

[51] B. J. Stocks, "Fire behaviour in mature jack pine," Canadian Journal of Forest Research, vol. 19, no. 6, pp. 783-790, 1989.

[52] D. X. Viegas and L. P. Pita, "Fire spread in canyons," International Journal of Wildland Fire, vol. 13, no. 3, pp. 253274, 2004.

[53] P. J. Woodburn and D. D. Drysdale, "Fires in inclined trenches: the dependence of the critical angle on the trench and burner geometry," Fire Safety Journal, vol. 31, no. 2, pp. 143-164, 1998.

[54] Y. Wu, H. J. Xing, and G. Atkinson, "Interaction of fire plume with inclined surface," Fire Safety Journal, vol. 35, no. 4, pp. 391-403, 2000.

[55] J. W. Dold and A. Zinoviev, "Fire eruption through intensity and spread rate interaction mediated by flow attachment," Combustion Theory and Modelling, vol. 13, no. 5, pp. 763793, 2009.

[56] N. P. Cheney and J. S. Gould, "Fire growth in grassland fuels," International Journal of Wildland Fire, vol. 5, pp. 237-247, 1995.

[57] F. E. Fendell and M. F. Wolff, "Wind-aided fire spread," in Forest Fires: Behavior and Ecological Effects, E. A. Johnson and K. Miyanishi, Eds., pp. 171-223, Associated Press, 2001.

[58] B. M. Wotton, R. S. McAlpine, and M. W. Hobbs, "The effect of fire front width on surface fire behavior," International Journal of Wildland Fire, vol. 9, no. 4, pp. 247-253, 1999.

[59] J. W. Dold, A. Zinoviev, and R. O. Weber, "Nonlocal flow effects in bushfire spread rates," in Proceedings of the 5th International Conference on Forest Fire Research, Coimbra, Portugal, 2006.

[60] R. K. Smith, B. R. Morton, and L. M. Leslie, "The role of dynamic pressure in generating fire wind," Journal of Fluid Mechanics, vol. 68, no. 1, pp. 1-9, 1975.

[61] H. Baum and B. McCaffrey, "Fire induced flow field-theory and experiment," Fire Safety Science, vol. 2, pp. 129-148, 1989.

[62] K. G. Tolhurst and N. P. Cheney, "Synopsis of the knowledge used in prescribed burning in Victoria," Tech. Rep., Department of Natural Resources and Environment, Fire Management, Victoria, Australia, 1999.

[63] C. E. Van Wagner, "Effect of slope on fires spreading downhill," Canadian Journal of Forest Research, vol. 18, pp. 818-820, 1988.

[64] W. R. Beaufait, "Characteristics of backfires and headfires in a pine needle fuel bed," Research Note INT-39, Intermountain Forest and Range Experiment Station, 1965.

[65] E. A. Catchpole, N. J. DeMestre, and A. M. Gill, "Intensity of fire at its perimeter," Australian Forest Research, vol. 12, pp. 47-54, 1982.

[66] F. A. Albini, "A model for the wind-blown flame from a line fire," Combustion and Flame, vol. 43, pp. 155-174, 1981.

[67] R. M. Nelson and C. W. Adkins, "Flame characteristics of wind-driven surface fires," Canadian Journal of Forest Research, vol. 16, pp. 1293-1300, 1986.

[68] D. R. Weise and G. S. Biging, "Effects of wind velocity and slope on flame properties," Canadian Journal of Forest Research, vol. 26, no. 10, pp. 1849-1858, 1996.

[69] J. R. Welker, O. A. Pipkin, and C. M. Sliepcevich, "The effect of wind on flames," Fire Technology, vol. 1, no. 2, pp. 122-129, 1965. 
[70] J. R. Welker and C. M. Sliepcevich, "Bending of wind-blown flames from liquid pools," Fire Technology, vol. 2, no. 2, pp. 127-135, 1966.

[71] O. A. Pipkin and C. M. Sliepcevich, "Effect of wind on buoyant diffusion flames: initial correlation," Industrial and Engineering Chemistry Fundamentals, vol. 3, no. 2, pp. 147154, 1964.

[72] R. E. Martin, M. A. Finney, D. M. Molina et al., "Dimensional analysis of flame angles versus wind speed," in Proceedings of the 11th Conference on Fire and Forest Meteorology, P. L. Andrews and D. Potts, Eds., Society of American Foresters, Missoula, Mont, USA, April 1991.

[73] F. Nmira, J. L. Consalvi, P. Boulet, and B. Porterie, "Numerical study of wind effects on the characteristics of flames from non-propagating vegetation fires," Fire Safety Journal, vol. 45, no. 2, pp. 129-141, 2010.

[74] J. Rios, Interaction effects of wind-blown proximate flames from burning wood cribs, Ph.D. thesis, University of Oklahoma, 1966.

[75] J. Rios, J. R. Welker, and C. M. Sliepcevich, "Interaction effects of wind-blown flames from wood crib fires," Fire Technology, vol. 3, no. 2, pp. 129-136, 1967.

[76] L. Pera and B. Gebhart, "Laminar plume interactions," Journal of Fluid Mechanics, vol. 68, no. 2, pp. 259-271, 1975.

[77] B. Gebhart, H. Shaukatullah, and L. Pera, "The interaction of unequal laminar plane plumes," International Journal of Heat and Mass Transfer, vol. 19, no. 7, pp. 751-756, 1976.

[78] J. B. Marsden-Smedley, W. R. Catchpole, and A. Pyrke, "Fire modeling in Tasmanian buttongrass moorlands. IV. Sustaining versus non-sustaining fire," International Journal of Wildland Fire, vol. 10, no. 2, pp. 255-262, 2001.

[79] J. K. Brown, "Fuel and fire behavior prediction in big sagebrush," Research Paper INT-290, USDA Forest Service, Intermountain Forest and Range Experiment Station, Ogden, Utah, USA, 1982.

[80] N. Burrows, B. Ward, and A. Robinson, "Fire behaviour in spinifex fuels on the Gibson Desert Nature Reserve, Western Australia," Journal of Arid Environments, vol. 20, no. 2, pp. 189-204, 1991.

[81] R. A. Bradstock and A. M. Gill, "Fire in semi-arid Mallee shrublands: size of flames from discrete fuel arrays and their role in the spread of fire," International Journal of Wildland Fire, vol. 3, no. 1, pp. 3-12, 1993.

[82] D. R. Weise, X. Zhou, L. Sun, and S. Mahalingam, "Fire spread in chaparral: 'go or no-go," International Journal of Wildland Fire, vol. 14, no. 1, pp. 99-106, 2005.

[83] C. E. Van Wagner, "Conditions for the start and spread of crown fire," Canadian Journal of Forest Research, vol. 7, pp. 23-34, 1977.

[84] A. D. Bruner and D. A. Klebenow, "Predicting success of prescribed fires in pinyon-juniper woodland in Nevada," Research Paper INT-219, USDA Forest Service, 1979.

[85] M. Vogel and F. A. Williams, "Flame propagation along matchstick arrays," Combustion Science and Technology, vol. 1, pp. 429-436, 1970.

[86] R. O. Weber, "A model for fire propagation in arrays," Mathematical and Computer Modelling, vol. 13, no. 12, pp. 95-102, 1990.

[87] T. Beer, "Fire propagation in vertical stick arrays: the effects of wind," International Journal of Wildland Fire, vol. 5, no. 1, pp. 43-49, 1995.
[88] M. A. Finney, J. D. Cohen, K. M. Yedinak, and I. C. Grenfell, "An examination of fire spread thresholds in discontinuous fuel beds," International Journal of Wildland Fire, vol. 19, no. 2, pp. 163-170, 2010.

[89] J. L. Beverly and B. M. Wotton, "Modelling the probability of sustained flaming: predictive value of fire weather index components compared with observations of site weather and fuel moisture conditions," International Journal of Wildland Fire, vol. 16, no. 2, pp. 161-173, 2007.

[90] S. Leonard, "Predicting sustained fire spread in tasmanian native grasslands," Environmental Management, vol. 44, no. 3, pp. 430-440, 2009.

[91] H. E. Anderson, “The sundance fire," USDA Forest Service Research Paper INT-56, 1968.

[92] D. J. McRae, J. Z. Jin, S. G. Conard, A. I. Sukhinin, G. A. Ivanova, and T. W. Blake, "Infrared characterization of finescale variability in behavior of boreal forest fires," Canadian Journal of Forest Research, vol. 35, no. 9, pp. 2194-2206, 2005.

[93] D. Morvan, C. Hoffman, F. Rego, and W. Mell, "Numerical simulation of the interaction between two fire fronts in the context of suppression fire operations," in Proceedings of the 8th Symposium on Fire and Forest Metrology, Kalispell, Mont, USA, October 2009.

[94] J. B. Marsden-Smedley, Planned Burning in Tasmania: Operational Guidelines and Review of Current Knowledge, Fire Management Section, Parks and Wildlife Service, Department of Primary Industries, Parks, Water and the Environment, Hobart, Australia, 2009.

[95] R. J. Taylor, S. T. Evans, N. K. King, E. T. Stephens, D. R. Packham, and R. G. Vines, "Convective activity above a largescale bushfire," Journal of Applied Meteorology, vol. 12, no. 7, pp. 1144-1150, 1973.

[96] A. G. McArthur, "The Tasmanian bushfires of 7th February, 1967, and associated fire behavior characteristics," in Mass Fire Symposium, Defense Standards Laboratory, Canberra, Australia, 1969, Paper A7.

[97] D. D. Wade and D. E. Ward, "An analysis of the Airforce Bomb Range Fire," USDA Forest Service Research Paper SE105, 1973.

[98] D. Weihs and R. D. Small, "Interactions and spreading of adjacent large area fires," Tech. Rep. DNA-TR-86-214, Pacific-Sierra Research, 1986.

[99] R. Baldwin, "Flame merging in multiple fires," Combustion and Flame, vol. 12, no. 4, pp. 318-324, 1968.

[100] O. Sugawa and W. Takahashi, "Flame height behavior from multi-fire sources," Fire and Materials, vol. 17, no. 3, pp. 111117, 1993.

[101] N. Liu, Q. Liu, Z. Deng, K. Satoh, and J. Zhu, "Burn-out time data analysis on interaction effects among multiple fires in fire arrays," Proceedings of the Combustion Institute, vol. 31, pp. 2589-2597, 2007.

[102] A. A. Putnam and C. F. Speich, "A model study of the interaction of multiple turbulent diffusion flames," Symposium (International) on Combustion, vol. 9, no. 1, pp. 867-877, 1963.

[103] Y. Fukuda, D. Kamikawa, Y. Hasemi, and K. Kagiya, "Flame characteristics of group fires," Fire Science and Technology, vol. 23, no. 2, pp. 164-169, 2004.

[104] M. Delichatsios, "A correlation for the flame height in "group" fires," Fire Science and Technology, vol. 26, no. 1, pp. $1-8,2007$.

[105] R. Baldwin, P. H. Thomas, and H. G. G. Wraight, "The merging of flames from separate fuel beds," Fire Research Note 
551, Fire Research Station, Boreham Wood, Hertfordshire, UK, 1964.

[106] R. Baldwin, "Some tentative calculations of flame merging in mass fires," Fire Research Note 629, Fire Research Station, Boreham Wood, Hertfordshire, UK, 1966.

[107] P. H. Thomas, "On the development of urban fires from multiple ignitions," Fire Research Note 699, Fire Research Station, Boreham Wood, Hertfordshire, UK, 1968.

[108] G. Heskestad, "A reduced-scale mass fire experiment," Combustion and Flame, vol. 83, no. 3-4, pp. 293-301, 1991.

[109] M. A. Fosberg, "Evaluation of the natural length scale in mass fires," in Proceedings of the Tripartite Technical Cooperation Program Panel N-3 (Thermal Radiation) Mass Fire Research Symposium, DASA, 1949, DASA Information and Analysis Center Special Report 59, 1967.

[110] R. I. Emori and K. Saito, "A study of scaling laws in pool and crib fires," Combustion Science and Technology, vol. 31, pp. 217-231, 1983.

[111] K. G. Huffman, J. R. Welker, and C. M. Sliepcevich, "Interaction effects of multiple pool fires," Fire Technology, vol. 5, no. 3, pp. 225-232, 1969.

[112] J. Grumer and A. Strasser, "Uncontrolled fires-specific burning rates and induced air velocities," Fire Technology, vol. 1, no. 4, pp. 256-268, 1965.

[113] D. Kamikawa, W. G. Weng, K. Kagiya, Y. Fukuda, R. Mase, and Y. Hasemi, "Experimental study of merged flames from multifire sources in propane and wood crib burners," Combustion and Flame, vol. 142, no. 1-2, pp. 17-23, 2005.

[114] N. Liu, Q. Liu, J. S. Lozano et al., "Global burning rate of square fire arrays: experimental correlation and interpretation," Proceedings of the Combustion Institute, vol. 32, pp. 2519-2526, 2009.

[115] H. W. Emmons, "Fundamental problems of the free burning fire," Symposium (International) on Combustion, vol. 10, no. 1, pp. 951-964, 1965.

[116] A. M. Grishin, A. N. Golovanov, and YA. V. Sukov, "Physical modeling of firestorms," Doklady Physics, vol. 49, no. 3, pp. 191-193, 2004.

[117] B. McCaffrey, "Flame heights," in SFPE Handbook of Fire Protection Engineering, National Fire Protection Association, Quincy, Mass, USA, 2nd edition, 1995.

[118] J. G. Quintiere and B. S. Grove, "A unified analysis for fire plumes," Proceedings of the Combustion Institute, vol. 27, pp. 2757-2766, 1998.

[119] N. A. Chigier and G. Apak, "Interaction of multiple turbulent diffusion flames," Combustion Science and Technology, vol. 10, no. 5-6, pp. 219-231, 1975.

[120] W. G. Weng, D. Kamikawa, Y. Fukuda, Y. Hasemi, and K. Kagiya, "Study on flame height of merged flame from multiple fire sources," Combustion Science and Technology, vol. 176, no. 12, pp. 2105-2123, 2004.

[121] P. H. Thomas, "The size of flames from natural fires," Symposium (International) on Combustion, vol. 9, no. 1, pp. 844-859, 1963.

[122] S. J. Tarr and G. Allen, "Flame interactions," Final Technical Report on Performance Prediction in Advanced Coal Fired Boilers JOF3-CT95-0005, International Combustion Limited, Rolls Royce Industrial Power Group, 1998.

[123] G. Heskestad, "Fire plumes, flame height, and air entrainment," in SFPE Handbook of Fire Protection Engineering, National Fire Protection Association, Quincy, Mass, USA, 4th edition, 2008.

[124] R. Roxburgh and G. Rein, "Study of wildfire in-draft flows for counter fire operations ,"WIT Transaction on Ecology and the Environment, vol. 119, pp. 13-22, 2008, Proceedings of Forest Fires: Modelling, Monitoring and Management of Forest Fires, Toledo, Ohio, USA, September 2008.

[125] R. O. Weber and J. W. Dold, "Linking landscape fires and local meteorology-a short review," JSME International Journal B, vol. 49, no. 3, pp. 590-593, 2006.

[126] T. Y. Palmer, "Large fire winds, gases and smoke," Atmospheric Environment, vol. 15, no. 10-11, pp. 2079-2090, 1981.

[127] J. S. Adams, D. W. Williams, and J. Tregellas-Williams, "Air velocity, temperature, and radiant-heatmeasurements within and around a large free-burning fire," Symposium (International) on Combustion, vol. 14, no. 1, pp. 1045-1052, 1973.

[128] J. Trelles and P. J. Pagni, "Fire induced winds in the 20 October Oakland Hills fire," Fire Safety Science, vol. 5, pp. 911-922, 1997.

[129] C. R. Church, J. T. Snow, and J. Dessens, "Intense atmospheric vortices associated with a 1000 MW fire," Bulletin American Meteorological Society, vol. 61, no. 7, pp. 682-694, 1980.

[130] D. J. McRae and M. D. Flannigan, "Development of large vortices on prescribed fires," Canadian Journal of Forest Research, vol. 20, no. 12, pp. 1878-1887, 1990.

[131] T. Ohlemiller and D. Corley, "Heat release rate and induced wind field in a large scale fire," Combustion Science and Technology, vol. 97, pp. 315-330, 1994.

[132] S. Soma and K. Saito, "Reconstruction of fire whirls using scale models," Combustion and Flame, vol. 86, no. 3, pp. 269284, 1991.

[133] W. M. G. Malalasekera, H. K. Versteeg, and K. Gilchrist, "A review of research and an experimental study on the pulsation of buoyant diffusion flames and pool fires," Fire and Materials, vol. 20, no. 6, pp. 261-271, 1996.

[134] G. Carrier, F. Fendell, and P. Feldman, "Big fires," Combustion Science and Technology, vol. 39, pp. 135-162, 1984.

[135] A. F. Ghoniem, I. Lakkis, and M. Soteriou, "Numerical simulation of the dynamics of large fire plumes and the phenomenon of puffing," Symposium (International) on Combustion, vol. 26, no. 1, pp. 1531-1539, 1996.

[136] G. M. Byram and R. M. Nelson, "The modeling of pulsating fires," Fire Technology, vol. 6, no. 2, pp. 102-110, 1970.

[137] B. M. Cetegen and T. A. Ahmed, "Experiments on the periodic instability of buoyant plumes and pool fires," Combustion and Flame, vol. 93, no. 1-2, pp. 157-184, 1993.

[138] S. R. Tieszen, "On the fluid mechanics of fires," Annual Review of Fluid Mechanics, vol. 33, pp. 67-92, 2001.

[139] R. M. Banta, L. D. Olivier, E. T. Holloway et al., "Smokecolumn observations from two forest fires using Doppler lidar and Doppler radar," Journal of Applied Meteorology, vol. 31, no. 11, pp. 1328-1348, 1992.

[140] M. Castellnou, M. Kraus, M. Miralles, and G. Delogu, "Suppression fire use in learning organizations," in Towards Integrated Fire Management-Outcomes of the European Project Fire Paradox, J. S. Silva, F. Rego, P. Fernandes, and E. Rigolot, Eds., chapter 5.2, European Forest Institute Research Report 23, Joensu, Finland, 2010.

[141] G. M. Byram, "Scaling laws for modeling mass fires," Pyrodynamics, vol. 4, pp. 271-284, 1966.

[142] P. H. Thomas, R. Baldwin, and C. R. Theobald, "Some model scale experiments with multiple fires," Fire Research Note 700, Fire Research Station, Boreham Wood, Hertfordshire, UK, 1968. 

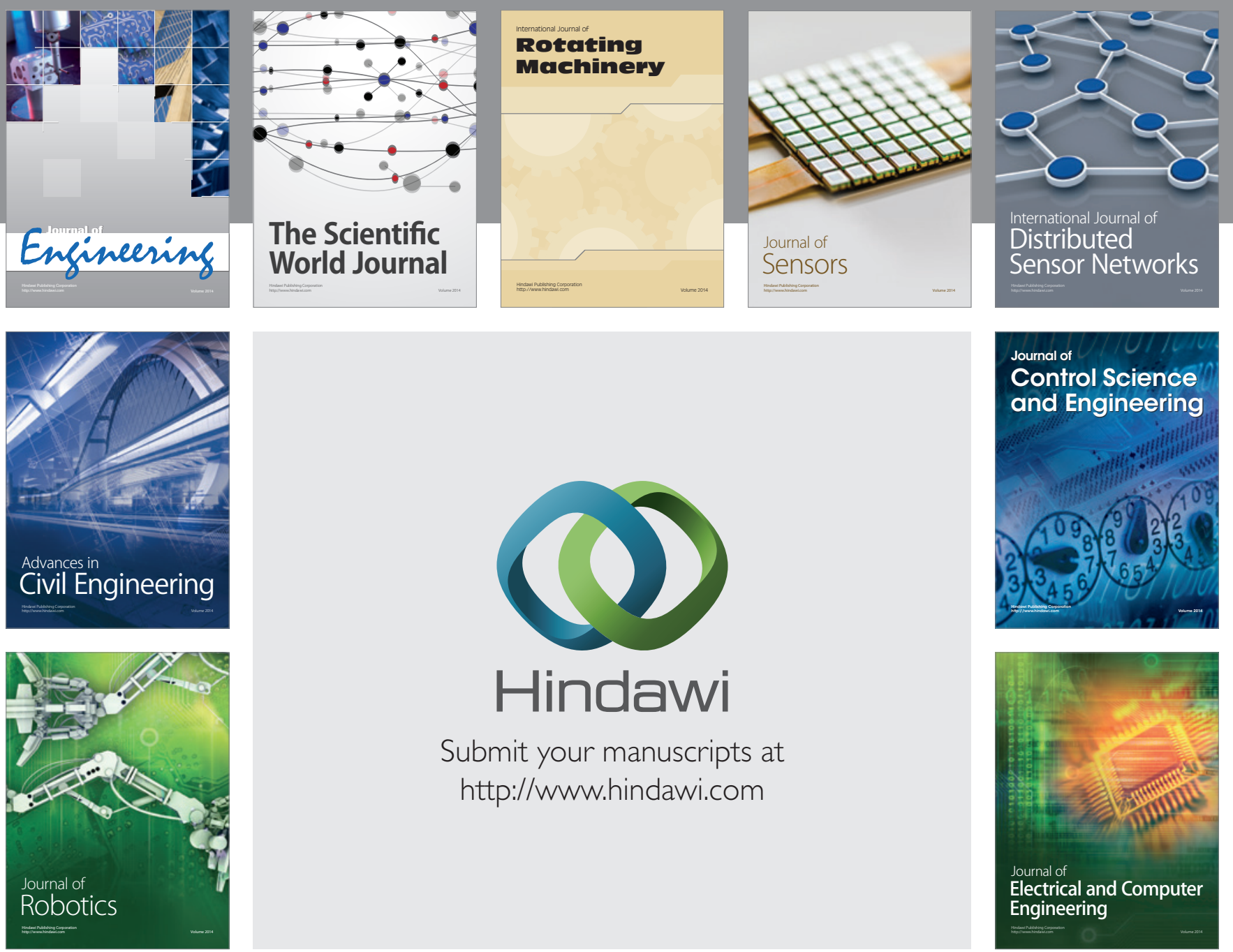

Submit your manuscripts at

http://www.hindawi.com
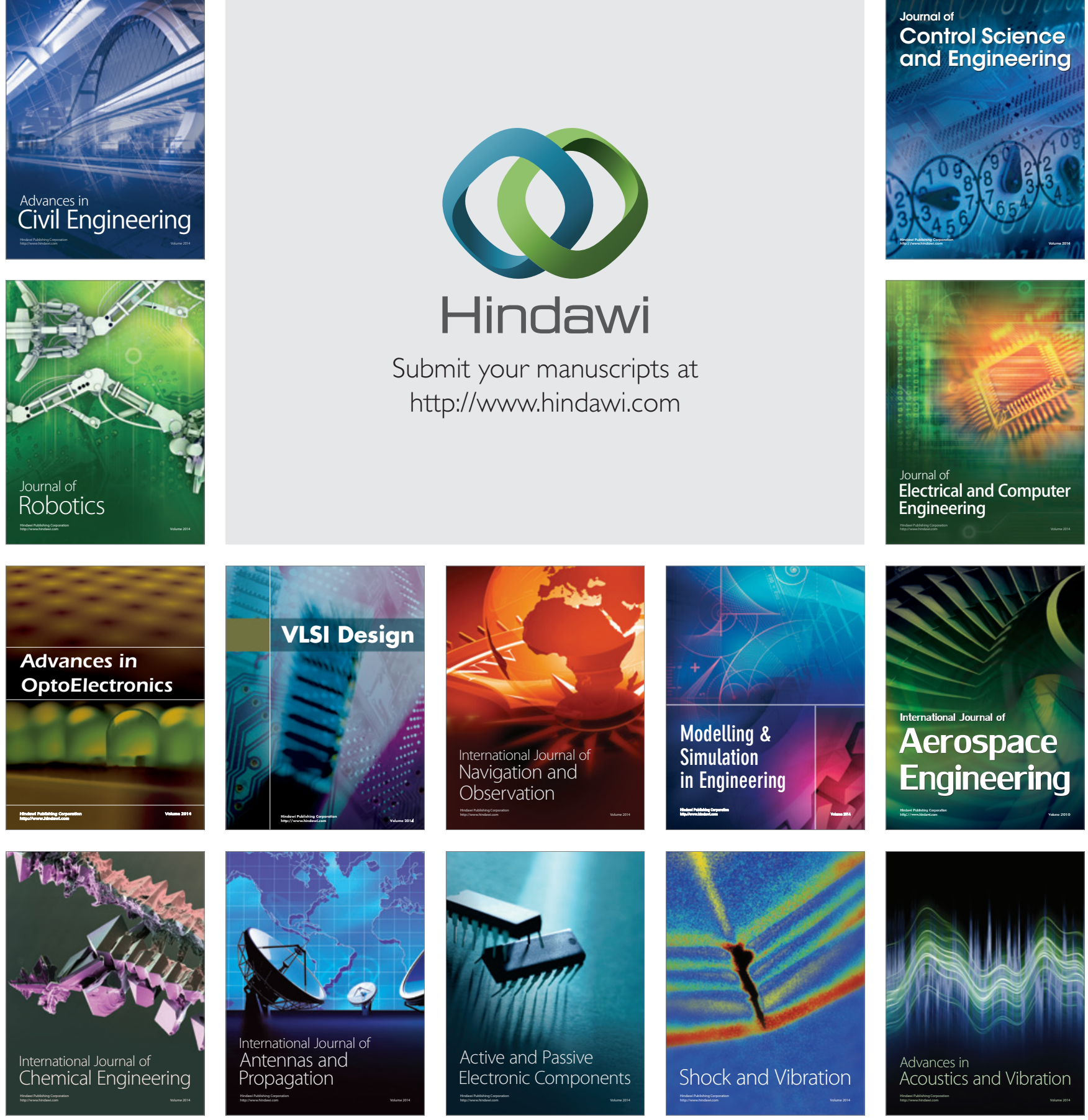